\title{
The sustainable building code as tool of management and protection of the rural areas of Abruzzo: a case study
}

\author{
P. De Berardinis \& M. Rotilio \\ Department of Architecture and Urbanism, L'Aquila University, Italy
}

\begin{abstract}
Today, most of the building heritage of historical centres does not meet the users' needs and is mostly in a state of physical decay. Moreover, the contemporary design process is giving more and more attention to the relationship between the building and the site and casting light on all the aspects of sustainability found in the pre-industrial settling. That's why it is very important to focus on the kind of action to take with respect to the construction of new buildings, but above all, with respect to the built heritage.

The introduction of sustainability in the heritage preservation process is complex because, besides the energetic, technical and plant engineering aspects, we need to consider the cultural problems arising when the architectural and environmental values do not allow any invasive actions. For this reason, the legislative tools that will be established to govern the building rehabilitation activity must focus on the research of compatibility. To achieve it, it will be necessary to take into account the values to preserve through a deep knowledge of the local building fabric and to analyse each case with particular care. This attention to all aspects of each intervention is fundamental as it means not simply to comply with certain standards or "numbers", but to go deeper because the ways in which a building was used in the past differ from those of today, as well as the users' needs of the past not being the same as today's. A flexible attitude of this kind is the key to avoiding situations where the effort made in research to develop strategies and criteria for the rehabilitation building process is cancelled out by improper legislative tools used by the municipalities in urban planning and heritage building management.
\end{abstract}

Keywords: building code, heritage preservation, values, compatibility, rehabilitation building process. 


\section{Introduction}

The countless historical minor centres, settled in the country, in the valleys, on the hills or perched on the mountains, are the "gemstones" of our territory and are a significant part of our national landscape.

These centres can be considered as having a value, not only as artistic and historical assets within the walls, but in particular for their unity and integrity, resulting from the historical stratification of urban fabric and spaces, the total value of the urban form and the indissoluble relationship with the territory [1].

Actually, these minor centres are considered as historical and architectural heritage, but there is still a gap in the national consciousness caused by a lack in the public awareness, culture, education and above all in the safeguard initiatives promoted by the competent authorities.

This lack of attention causes permanent degradation in those centres that, because of the changes in the economic and settling organization, have lost their role in the productive and social life of the territory.

This concept, unfortunately, affects the inner areas of the Abruzzo territory. In fact these internal areas are currently being abandoned as a result of the area's geographical isolation and difficulties in communication, all leading to a static economy. The direct consequences of this phenomenon have been a fall in productivity and deterioration in housing across hundreds of small centres within the region. The means of halting this state of deterioration, and promoting a "physical" recovery of historical centres has been discussed and debated for many years [2]. In real terms what must be overcome is the idea that these centres are no longer relevant to the territory and new ways must be found for revitalizing them, as they represent the region's social and cultural heritage and their loss would be a loss for society as a whole. Physical recovery must, therefore, be accompanied by new social and economical roles given that those of the past are no longer viable [3].

The adoption of energy and environmental strategies, which can improve the use of historical centres, must also be taken into consideration if only for the fact that the needs of today's society are not those of the past.

This task must be carried out with preservation of values at the forefront of and in light of the transformability of elements, the climatic and natural context, local resources, the re-discovery of old building techniques and new technical and technological solutions. In other words, rehabilitation must be based on the principles of sustainability. The introduction of these principles is complex because, besides the energetic, technical and plant engineering aspects, we need to consider the cultural problems arising when the architectural and environmental values do not allow any invasive actions.

Hence the need for carefully studied norms that incorporate sustainability as recent European legislation has indicated. In fact, one of the main objectives established by Agenda 21 to reduce energy consumption was the setting up of projects to contain emissions and improve energy efficiency, including requalification of existing building heritage and the rehabilitation of buildings in historical contexts. 
Furthermore, the same European Directive 2002/91/CE sets down guidelines concerning the development of systems and technology including innovation, to monitor environmental performances of building in order to rationalize the use of resources and maintain the comfort conditions.

\section{Analysis}

From the analysis of the historical settlements, we can understand how the aspects of sustainability were already present in the construction process and how they were used, not by choice, but from necessity.

The idea of construction as an ecosystem is present in traditional practices where an empirical approach was adopted and perfected in daily life. Traditional know-how was handed down from father to son and it was experience that led to technological solutions, rather than theoretical models. These solutions were based on in-depth knowledge, perfected over time.

They took into account environmental context, climate, and local materials and gave life to the specific language of the site taken into examination, forging a strong bond between building and nature.

The great confidence in technology led to the refusal to follow traditional principles and led to the birth of a dissipative architecture which did not respect the building features and the surrounding site.

The contemporary design process is giving more and more attention to the relationship between the building and the site and casting light on all the aspects of sustainability found in the preindustrial settling, fig. 1, for both the construction of new buildings and rehabilitation of the built heritage.
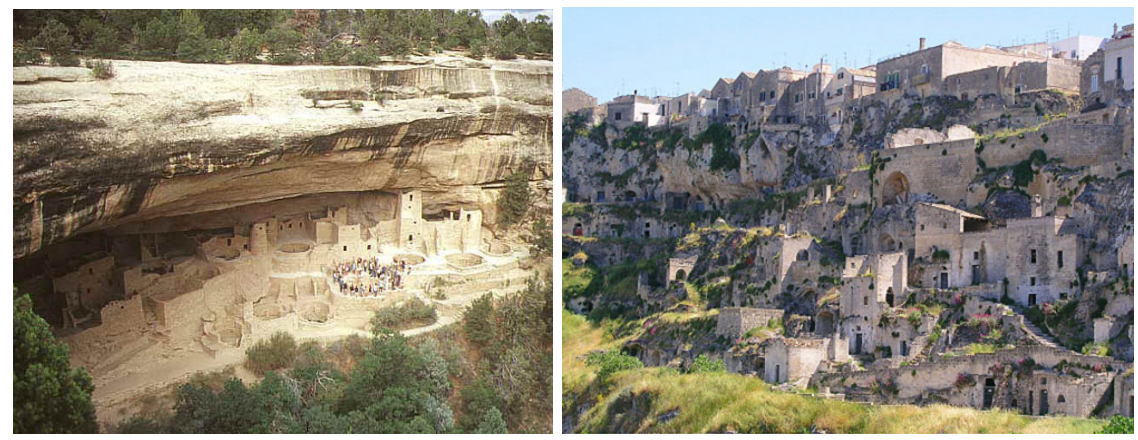

Figure 1: "Mesa Verde" and "Sassi di Matera" as examples of preindustrial settlings.

In fact, sustainability and rehabilitation have common roots [4], as both are based on the assumption that a careful use of resources, a wider penetration of renewable energy sources and a greater attention to the environmental aspect allow "sustainable development" as defined in the Brundtland Report (1987).

Although sustainability and rehabilitation can be successfully applied together to disused industrial sites and disused outskirts, where the nature of construction 
is more malleable, the same cannot be said for our minor centres. In these places, the presence of buildings of architectonic and environmental value does not allow any invasive actions, requiring a different approach.

When new technologies are used in architectural buildings with historical / aesthetic values, the attitude of contemporary culture is always hostile. This can be seen from the literature that actually offers very few excellent examples of the use of such new technologies. In fact, this is even more complex when the intervention involves the historical built fabric and not the single historical building, where we generally have the adequate knowledge of the design process and the methods of action.

Indeed, the rehabilitation process involves a variety of problems because it operates on already existing contexts (presence of ties, technical and structural restrictions) and this is more valid when we have to operate in contexts having historical, environmental, cultural and landscape values, fig. 2 .

Unfortunately, in most cases of rehabilitation and revitalisation of historical context, economic saving and formal conservation are the ruling principles often at the cost of genuineness and the quality of the work itself. Moreover, the lack of effective legislation tools justifies the indiscriminate and heterogeneous interventions and doesn't facilitate the respect of the cultural values handed down from our fathers. At this point we need a courageous recovery of the planning meaning and of the ability to invest in the project. This can be done by facing any problem as a whole by considering the subtle relations that bind the parties to each other and each of them to everything. Moreover, it is important to suggest 'new compatible' solutions and develop a sensitivity of non-invasive operations. It's a creative path, based on an in-depth knowledge of the place, its architecture and traditional building structures and materials, present in nature and in the site.
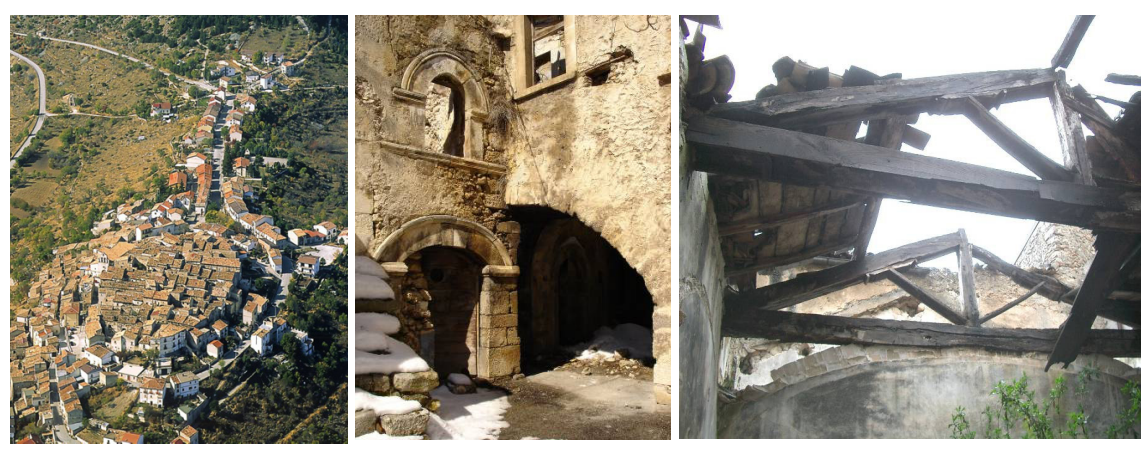

Figure 2: The minor centres as places with environmental, historical, spatial and architectural values.

It's a systematic approach that needs to be accomplished by using contemporary forms and procedures together with appropriate materials and finishes of the traditional culture. 
Finally, it is important to leave behind a deterministic and binding vision in order to adopt a flexible approach, so that the effort that has gone into research aimed at developing methodologies and intervention criteria is not thwarted by inadequate legislation at the disposition of local administrations for the planning and management of the building patrimony. In line with this, we are going to illustrate one solution of the main principles of sustainability to be introduced in the Building Code of the minor centre called Civitaretenga, L'Aquila, Italia.

\section{Case study - methodology}

The study of the legislative tools used by local councils as a reference and guide to promote the territory development do not take into account any elements of sustainability in building codes concerning contexts of environmental and historical value.

In fact, only in new or recent contexts in suburban areas, characterized often by conditions of total indifference towards their cultural and historical features, are there legislative rules that introduce principles of environmental sustainability into the 'Building Code'. On the contrary, in the historical contexts, the city councils have always denied any possibility of intervention to preserve the minor centres or at least suggested only particular ways of intervention.

With reference to the study of significant examples of rehabilitation, it was found that they always concerned the single historical building, for which adequate economic and methodological resources were generally available.

In conclusion, the study of the state of art has revealed the lack of significant points of reference when the intervention must be done on the built fabric of the minor centre.

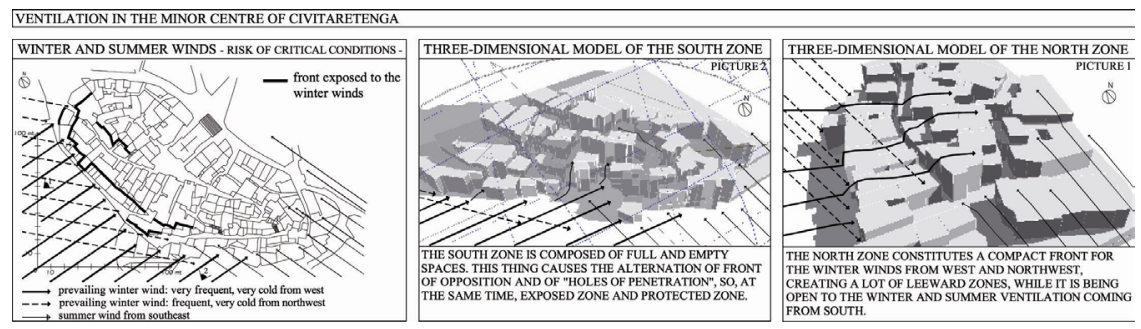

Figure 3: Study of the condition of ventilation in the minor centre of Civitaretenga.

Hence for this reason a strategy of action needs to be drawn up, based on a study of the context, allowing the system/building to reach its full potential whilst at the same time meeting the environmental requirements of today.

The strategy to adopt must respect the existing context with its architectural, historical, environmental values and find solutions to preserve the identity of the place by exploiting its climatic context as well as the most recent technological innovations. The methodology illustrated herein refers to the minor centre 
studied and will lead to the drawing up of a specific building code for the village itself. It will aim to identify compatible solutions that are not invasive.

The cognitive analysis should be the foundation of the building code and provide for general studies of the urban fabric, the constructive and building types that allow us to take into account the values to preserve and the elements to transform. At the same time the climate context and the environmental requirements to be met will be studied. The synthesis of these three aspects will lead to the identification of compatible solutions.

The environmental investigation consisted of: a bioclimatic study looking at the degree of sunshine and ventilation, fig. 3, and any relationships between the urban fabric and climate, fig. 4; and biophysical analyses of the land, vegetation and water basins. These were then used to draw up a map of "critical conditions" for winter, fig. 5, and summer highlighting zones at climate risk.

A further investigation will lead to the chart of the critical climatic mapping of the whole village, fig. 6 .

The objective of this chart is the definition of homogeneous zones in terms of bioclimatic and biophysical behaviour. This is a basic annex of the building code of Civitaretenga.

In parallel to the climatic studies, a map of 'values' was also drawn up for Civitaretenga through the study of features of decorative, cultural and historical value or in other words, of all the elements that a planner should protect and conserve so that they can be passed down to the next generation. This ties in closely to the study of the environment in that the continual presence over time of given critical conditions may be at the root of certain forms of degradation. Furthermore, the study of the state of conservation of the fabric is essential to establish what the element itself can offer, in terms of performances, and to determine its possible uses. Following the drawing up of the map of 'values' and in the light of the degradation observed, a transformability map can be prepared defining variables and areas for intervention, fig. 7 .

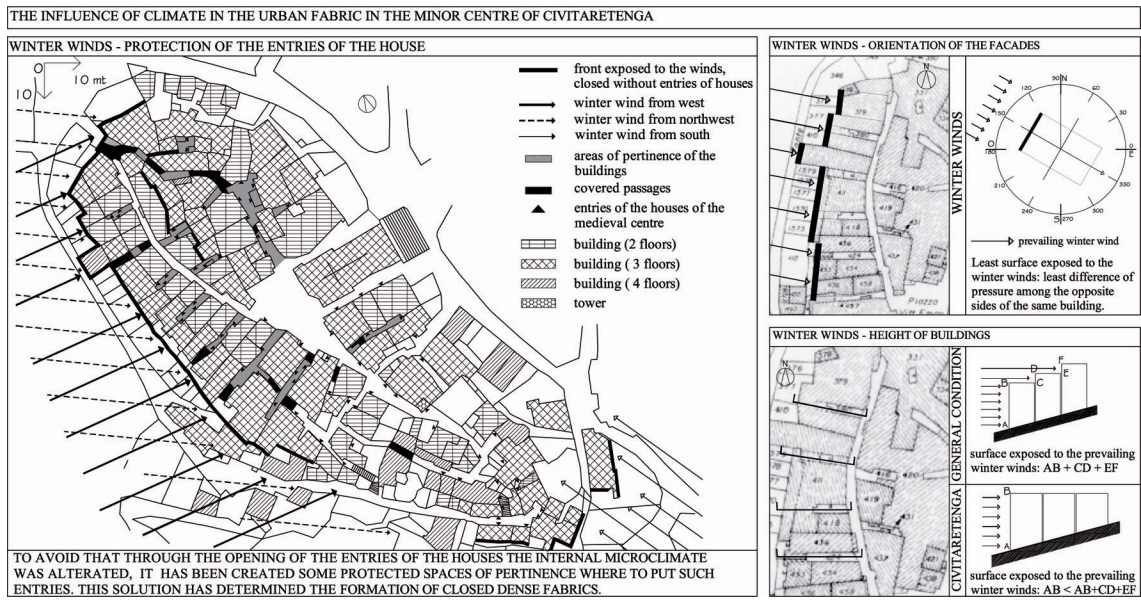

Figure 4: Study of the influence conditions of the climate in the urban fabric of Civitaretenga. 


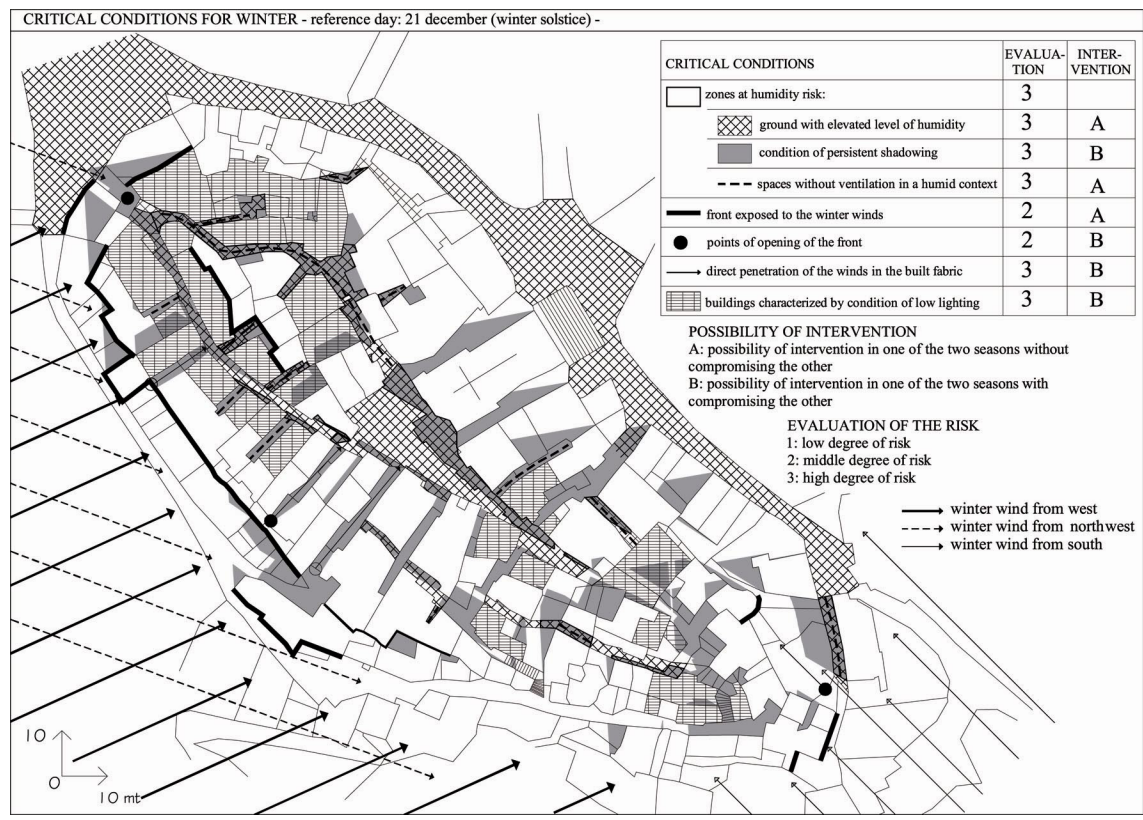

Figure 5: The map of the winter critical conditions concerning the minor centre of Civitaretenga.

These three maps, the chart of the critical climatic mapping, the map of 'values' and the transformability map, provide the designer with a context for the project.

It is important to underline at this point, that the rehabilitation process must ensure that the building is brought back to life and meets the needs of today's user, which are completely different to those of past occupants.

In fact the rehabilitation of historical buildings must entail reflection on new uses and needs also in terms of lighting comfort, hygrothermal comfort and acoustic one, fig. 8 .

In conclusion, because of the presence of several variables, the building code of the single minor centre must to be based on the process of compatibility between values, transformable elements, climatic conditions, users' needs and contemporary technological solutions. All these criteria have been applied into a case study.

An awareness of the territorial context and climate allows us to look for solutions that take advantage, for example, in the south zone ("E" zone) of the empty space system, in the north-east zone ("A" zone) of the built fabric which is closed, very compact and protect, in the west zone ("C" zone) of the built fabric which is like a grid, compact but very exposed to the winter wind. Thus the objectives to be highlighted in the south zone are interventions aimed at the rational use of energy and the use of renewable energy. 


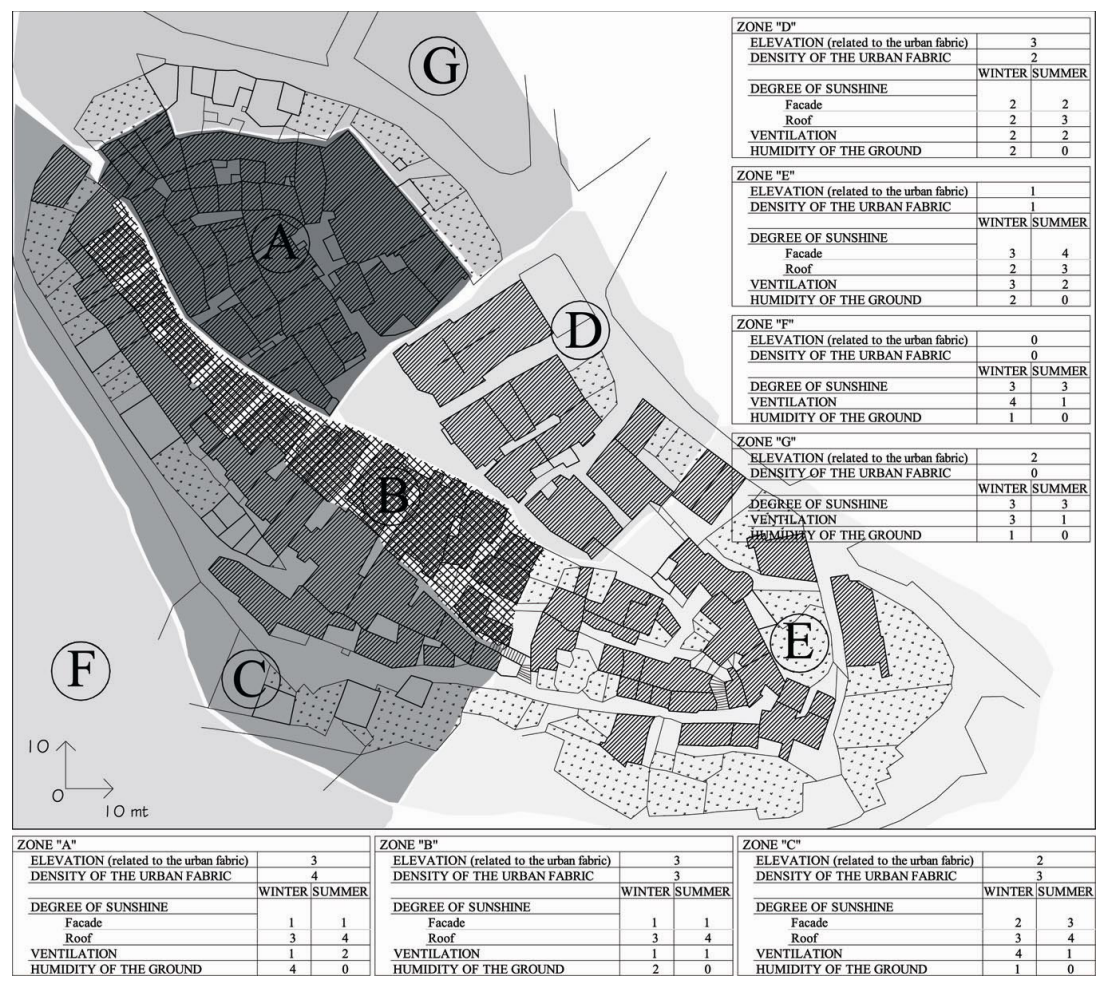

Figure 6: The "Chart of the critical climatic mapping" for the minor centre of Civitaretenga.

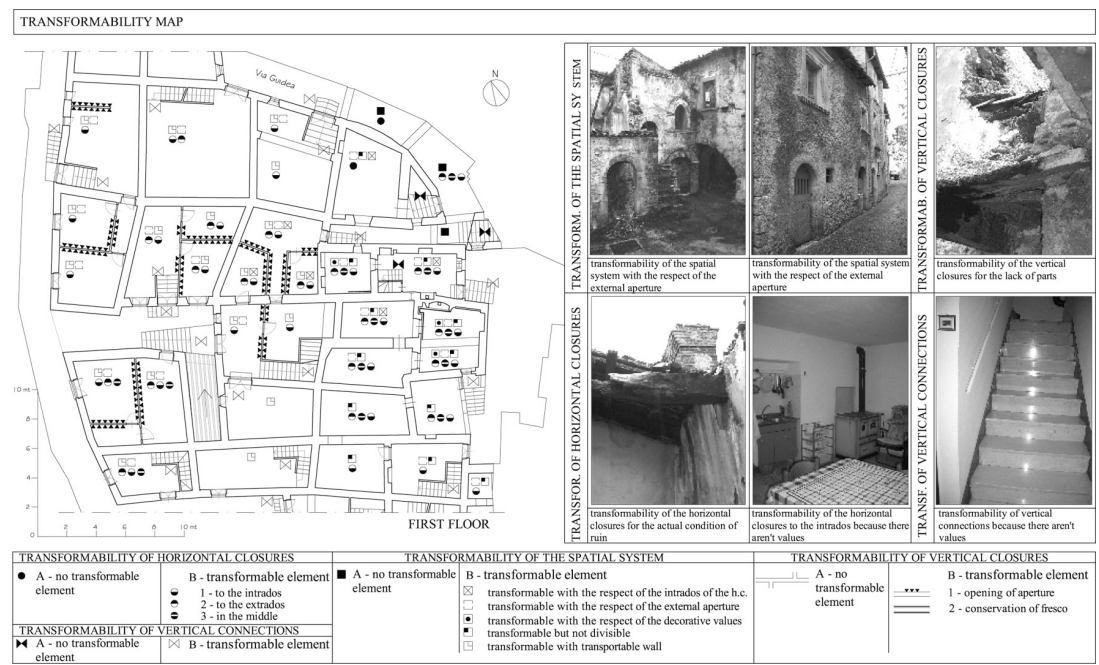

Figure 7: The "Transformabiliy map" concerning the minor centre of Civitaretenga. 


\begin{tabular}{|c|c|c|c|}
\hline \multicolumn{4}{|l|}{\begin{tabular}{|l} 
PLANNING STRATEGIES \\
\end{tabular}} \\
\hline SPECIFIC OBJECTIVES & STRATEGIES (ACTIONS) & DESIGN & COMPATIBILITY \\
\hline \multirow[t]{15}{*}{$\begin{array}{l}\text { HYGROTHERMAL } \\
\text { COMFORT }\end{array}$} & \multirow{3}{*}{ CONTROL OF CONDENSATION WATER } & \multirow[b]{2}{*}{ use of systems for collecting rainwater } & \multirow{3}{*}{1} \\
\hline & & & \\
\hline & & use of vegetable structures & \\
\hline & PROMOTE THE SOLAR RADIATION & use of light coloured pavings & 1 \\
\hline & REDUCE THE SOLAR RADIATION & introduction of passive thermal floors & 2 \\
\hline & & introduction of roof pond & 2 \\
\hline & $\begin{array}{l}\text { INCREASE HEAT INSULATION OF THE } \\
\text { OPAQUE ENVELOPE }\end{array}$ & introduction of solar greenhouse & 2 \\
\hline & INCREASE HEAT INSUL ATION OF THE & introduction of ventilated roofs & 2 \\
\hline & CLEAR ENVELOPE & introduction of "green" roofs & 2 \\
\hline & INCREASE THE THERMAL INERTIA & use of double glazing windows & 2 \\
\hline & CONTROL OF HUMIDITY & $\begin{array}{l}\text { use of "Transparent Insulation } \\
\text { Materials" }\end{array}$ & 2 \\
\hline & & introduction of the cross ventilation & 2 \\
\hline & PROMOTE THE SUMMER COOLING & introduction of internal heat insulation & 2 \\
\hline & $\begin{array}{l}\text { CONTROL OF THE INTERNAL } \\
\text { VENTILATION }\end{array}$ & & \\
\hline & $\begin{array}{l}\text { CONTROL OF THE EXPOSURE TO } \\
\text { THE WINDS }\end{array}$ & & \\
\hline \multicolumn{4}{|l|}{ LIGHTING COMFORT } \\
\hline & $\begin{array}{l}\text { CONTROL OF THE DIRECT AND } \\
\text { REFLECTED SOLAR RADIATION }\end{array}$ & $\begin{array}{l}\text { use of "Transparent Insulation } \\
\text { Materials" }\end{array}$ & 1 \\
\hline & \multirow[b]{2}{*}{ IMPROVE THE INTERNAL LIGHTING } & use of solar stacks & 1 \\
\hline & & introduction of skylight & 1 \\
\hline & AVOID GLARE & re-design of internal rooms & 2 \\
\hline & \multirow[b]{2}{*}{ DESIGN ROOMS CORRECTLY } & use of light coloured paints & 2 \\
\hline & & re-design of windows & 2 \\
\hline & \multirow[t]{6}{*}{ DESIGN WINDOWS CORRECTLY } & use of reflective shelf & 2 \\
\hline & & use of fixed brise-soleil & 2 \\
\hline & & use of movable brise-soleil & 2 \\
\hline & & use of the shadovoltaic system & 2 \\
\hline & & employment of the photovoltaic panels & 2 \\
\hline & & introduction of internal heat insulation & 2 \\
\hline
\end{tabular}

ACOUSTIC COMFORT

IN THE MINOR CENTRE OF

CIVITARETENGA THE ACOUSTIC

COMFORT WAS ALREADY

GUARANTEED THANKS TO THE LACK

OF POLLUTION SOURCES

Figure 8: Planning strategies. The rehabilitation of historical buildings must entail reflection on new uses and also needs in terms of lighting comfort, hygrothermal comfort and acoustics.

Strategies drawn up for achieving these aims encourage the planning of systems for collecting rainwater taking advantages of the natural inclinations present in this minor centre perched on a hillside, using equipment to be placed in the road network system. The water collected in tanks can then be used by the 
inhabitants in their houses, in the village fountains to promote the summer cooling, to irrigate public areas etc. The open spaces can easily be used to host solar energy equipment in a network or stand alone devices for home or public lighting.

In the north-east zone actions should encourage energy efficiency and the use of renewable energy sources thus achieving visual-lighting comfort. These aims can be achieved through the promotion of action aimed at improving energetic performances of the building envelope through building heat insulation, ventilated roofs, and solar greenhouse for south facing windows.

Renewable energy sources can also be promoted by placing appropriate devices on south facing slopes. Lastly, further positive lighting effects can be achieved in the open space through light coloured paving using local stone and the use of light coloured paints in pertinent areas.

Finally, in the west zone, actions should encourage the use of renewable energy and the achievement of the visual-lighting comfort as well as the introduction of systems to protect from the cold winter winds like the vegetable structures and the bioclimatic 'niches'.

This example underlines the need for contextualization of legislation, the need for legislation to promote compatible solutions.

Building code conceived and drafted according to the principles expressed herein would constitute a basis for planning and a support for preliminary projects. So, this instrument will be the guide for the following design phases.

\section{References}

[1] Rolli, G.L., Salvare i centri storici minori, proposte per un atlante urbanistico dei centri d'Abruzzo, Alinea: Firenze, pp. 11-18, 2008.

[2] Santini, C., Il campo normativo della ricerca (Chapter 1). Centri antichi minori d'Abruzzo, Recupero e valorizzazione, eds. S. Bonamico \& G. Tamburini, Gangemi: Roma, pp. 19-29, 1996.

[3] Rolli, G.L., I centri storici nella struttura territoriale. Il recupero dei ruoli funzionali (Chapter 6). Centri antichi minori d'Abruzzo, Recupero e valorizzazione, eds. S. Bonamico \& G. Tamburini, Gangemi: Roma, pp. 267-311, 1996.

[4] Fontana, C., Recupero e sostenibilità. Il progetto sostenibile, 2, pp. 4-11, 2004. 